\title{
KANSAS
}
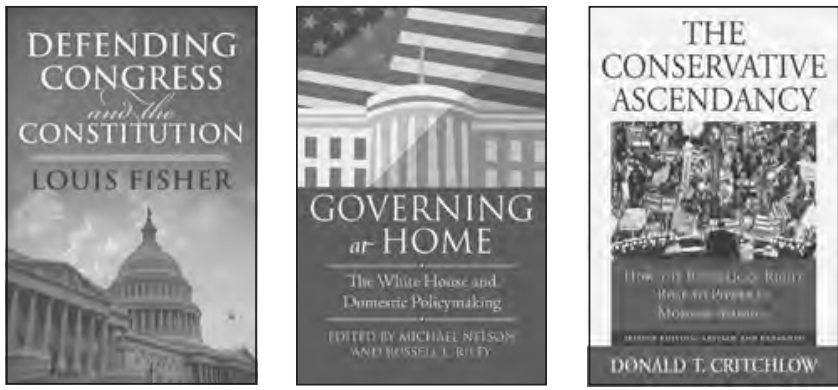

\section{Defending Congress and the Constitution}

Louis Fisher

"For forty years Louis Fisher has been a national treasure. His splendid new volume provides a fitting capstone to an extraordinary career."-Thomas Mann, coauthor of The Broken Branch: How Congress is Failing America and How to Get It Back on Track

376 pages, Cloth $\$ 39.95$, Paper $\$ 24.95$

\section{Governing at Home}

The White House and Domestic Policymaking Edited by Michael Nelson and Russell L. Riley

"Well conceived and superbly executed, Governing at Home is a good read and a fine reference that combines the scholarship of those studying domestic policymaking with the recollections of those experiencing it in the White House."-Charles O. Jones, author of The Presidency in a Separated System

336 pages, Cloth $\$ 39.95$, Paper $\$ 19.95$

\section{The Conservative Ascendancy}

How the Republican Right

Rose to Power in Modern

America

Second Edition, Revised and

Expanded

Donald T. Critchlow

Newly updated and available for the first time in paperback. Includes an entirely new chapter covering the 2008 presidential election, the 2008 financial meltdown, the first two years of Obama's presidency, the emergence of the Tea Party, the 2010 midterms, and ongoing economic problems.

400 pages, Paper $\$ 19.95$

\section{Introducing a new series:}

\section{Constitutional Thinking}

Jeffrey K. Tulis and Sanford Levinson, series editors

Books in the series will develop constitutional theory beyond legalistic concerns by examining such matters as institutional development; public policy; and political behavior, culture, and theory. The editorial approach, then, favors a constitutional theory embracing the full range of activities relevant to the making, maintenance, and reform of constitutions and constitutional cultures.

\section{Habeas Corpus in America} The Politics of Individual Rights

Justin J. Wert

"This is the best history of habeas corpus that I know of. It both confirms and extends important insights in American constitutional development, as well as providing vital information on a basic constitutional right."-Mark A. Graber, author of Dred Scott and the Problem of Constitutional Evil 302 pages, Cloth $\$ 34.95$

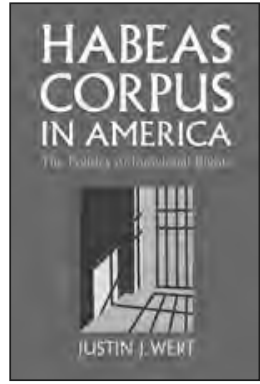

Landmark Law Cases and American Society Peter Charles Hoffer and N.E.H. Hull, series editors

\section{New York Times v. Sullivan}

Civil Rights, Libel Law, and the Free Press

Kermit L. Hall and

Melvin I. Urofsky

"An excellent and accessible book about an important moment in American history."-Steven F. Lawson, author of Civil Rights Crossroads

232 pages, Cloth $\$ 34.95$, Paper $\$ 17.95$

\section{The Constitutional Rights of Children} In re Gault and Juvenile Justice

David S. Tanenhaus

"A sophisticated and insightful account that tells the story of the last great battle in the due process revolution."-Franklin E. Zimring, author of American Juvenile Justice 176 pages, Cloth $\$ 29.95$, Paper $\$ 16.95$

\section{University Press of Kansas} Phone 785-864-4155 • Fax 785-864-4586 • www.kansaspress.ku.edu 


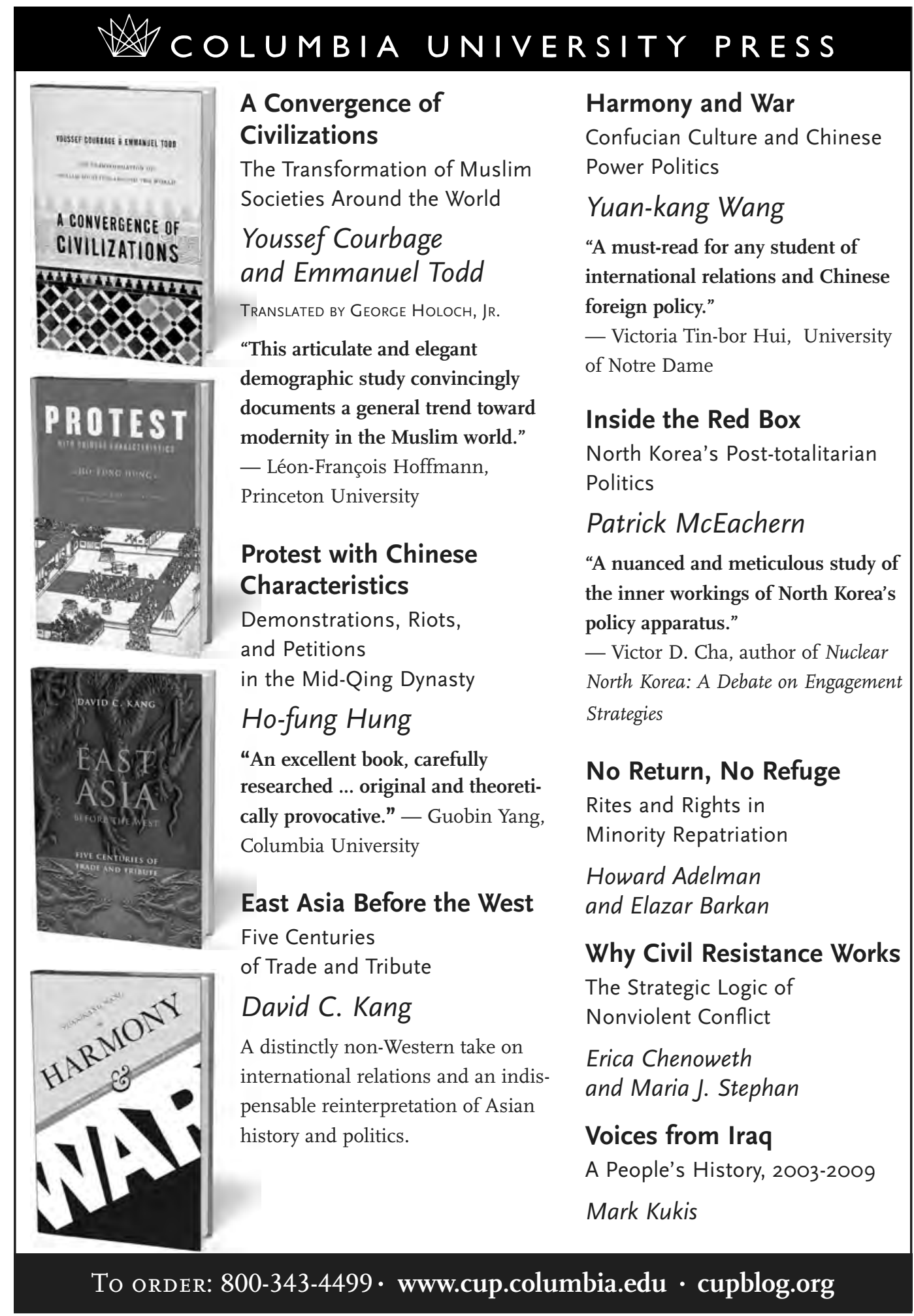




\section{New from BROOKINGS}

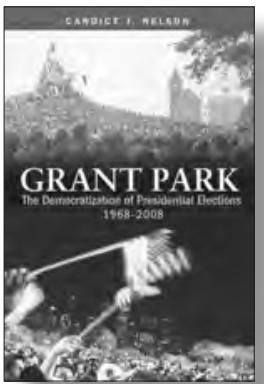

Grant Park The Democratization of Presidential Elections, 1968-2008

Candice J. Nelson

$188 \mathrm{pp}$.

paper, 978-0-8157-2184-0, \$24.95

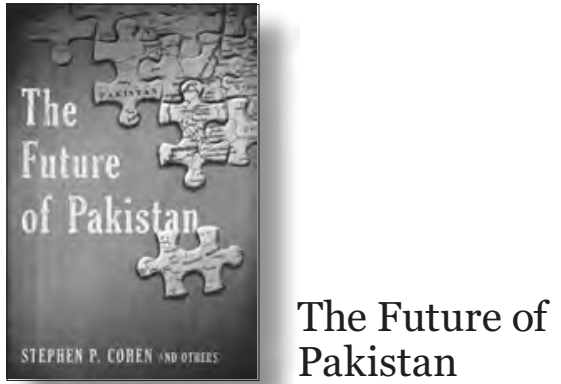

Stephen P. Cohen and others $325 \mathrm{pp}$.

paper, 978-0-8157-2180-2, \$29.95

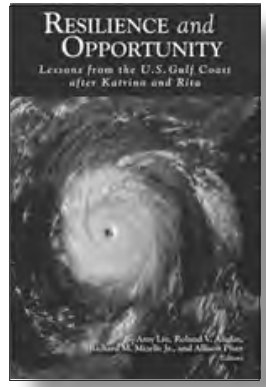

Resilience and Opportunity Lessons from the U.S. Gulf Coast after Katrina and Rita

Amy Liu, Roland V. Anglin, Richard M. Mizelle Jr., and Allison Plyer, eds.

$290 \mathrm{pp}$.

paper, 978-0-8157-2149-9, \$22.95

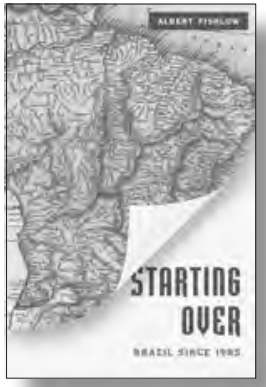

Albert Fishlow

$236 \mathrm{pp}$.

cloth, 978-0-8157-2143-7, \$34.95

$275 \mathrm{pp}$.

cloth, 978-0-8157-2212-0, \$29.95

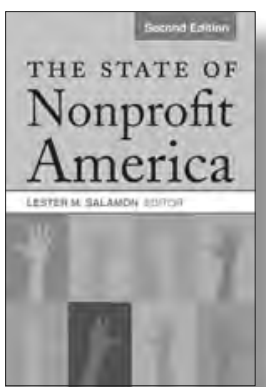

The State of Nonprofit America Second Edition Lester M. Salamon, ed. $575 \mathrm{pp}$. paper, 978-0-8157-0330-3, \$36.95

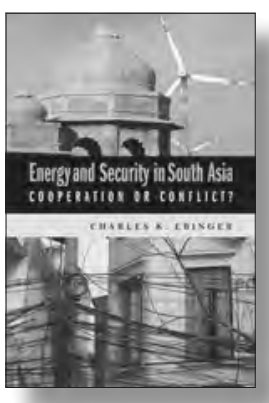

Energy and Security in South Asia Cooperation or Conflict?

Charles K. Ebinger

$224 \mathrm{pp}$.

paper, 978-0-8157-0411-9, \$26.95

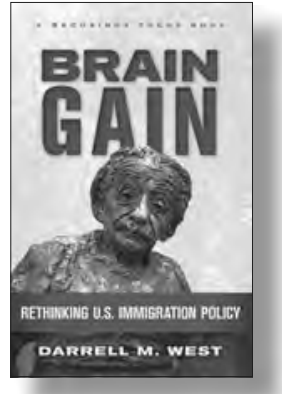

New in paperback Brain Gain Rethinking U.S. Immigration Policy With a new preface
Darrell M. West

A Brookings FOCUS Book $182 \mathrm{pp}$.

paper, 978-0-8157-2223-6, \$19.95

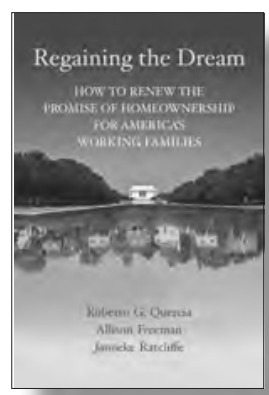

Regaining the Dream

How to Renew the Promise of Homeownership for America's Working Families

Roberto G. Quercia,

Allison Freeman, and Janneke Ratcliffe 160 pp.

paper, 978-0-8157-2172-7, \$19.95 


\section{What's New in Political Science?}

The Future of Representative Democracy

Edited by Sonia Alonso, John Keane, and Wolfgang Merkel

\$90.00: Hb: 978-1-107-00356-9: $322 \mathrm{pp}$. \$32.99: Pb: 978-0-521-17703-0

Islamist Terrorism and Democracy in the Middle East

Katerina Dalacoura

\$85.00: Hb: 978-0-521-86518-0: $224 \mathrm{pp}$ \$26.99: Pb: 978-0-521-68379-1

Mexico and its Diaspora in the United States

Policies of Emigration since 1848

Alexandra Delano

\$90.00: Hb: 978-1-107-01126-7: 304 pp.

\section{Agenda Setting}

in the U.S. Senate

Costly Consideration and

Majority Party Advantage

Chris Den Hartog and

Nathan W. Monroe

\$85.00: Hb: 978-1-107-00646-1: 252 pp.

Cambridge Handbook of Experimental Political

\section{Science}

Edited by James N. Druckman, Donald P. Green,

James H. Kuklinski, and

Arthur Lupia

\$125.00: Hb: 978-0-521-19212-5: $604 \mathrm{pp}$. \$48.00: Pb: 978-0-521-17455-8

Tocqueville:

The Ancien Régime and the French Revolution

Edited by Jon Elster

Translated by

Arthur Goldhammer

Cambridge Texts in the

History of Political Thought

\$75.00: Hb: 978-0-521-88980-3: $320 \mathrm{pp}$

\$19.99: Pb: 978-0-521-71891-2
American Politicians

Confront the Court

Opposition Politics and Changing

Responses to Judicial Power

Stephen M. Engel

\$99.00: Hb: 978-0-521-19295-8: 408 pp. \$32.99: Pb: 978-0-521-15398-0

\section{Gender, Nationalism,}

\section{and War}

Conflict on the Movie Screen

Matthew Evangelista

\$90.00: Hb: 978-1-107-00194-7: $304 \mathrm{pp}$ \$32.99: Pb: 978-0-521-17354-4

Symbols and Legitimacy in Soviet Politics

Graeme Gill

\$95.00: Hb: 978-1-107-00454-2: 362 pp.

The Invention of

Market Freedom

Eric MacGilvray

\$90.00: Hb: 978-1-107-00136-7: 216 pp. \$26.99: Pb: 978-0-521-17189-2

\section{Second Edition}

\section{Victory in War}

Foundations of Modern Strategy

William C. Martel

\$120.00: Hb: 978-1-107-01419-0: $592 \mathrm{pp}$. \$50.00: Pb: 978-0-521-17773-3

\section{Origins of}

\section{Political Extremism}

Mass Violence in the Twentieth Century and Beyond

Manus I. Midlarsky

\$99.00: Hb: 978-0-521-87708-4: 442 pp. \$36.99: Pb: 978-0-521-70071-9

\section{Domestic Law Goes Global}

Legal Traditions and

International Courts

Sara McLaughlin Mitchell and Emilia Justyna Powell

\$90.00: Hb: 978-1-107-00416-0: 280 pp.

\section{Public Management}

Organizations, Governance, and Performance

Laurence J. O'Toole, Jr. and

Kenneth J. Meier

\$73.00: Hb: 978-1-107-00441-2: 332 pp.
Decision Making by the Modern Supreme Court Richard L. Pacelle, Jr., Brett W. Curry, and Bryan W. Marshall

\$85.00: Hb: 978-0-521-88897-4: 280 pp. \$27.99: Pb: 978-0-521-71771-7

Israel's Palestinians

The Conflict Within

Ilan Peleg and Dov Waxman

\$85.00: Hb: 978-0-521-76683-8: 280 pp. \$27.99: Pb: 978-0-521-15702-5

\section{Superstition as Ideology}

in Iranian Politics

From Majlesi to Ahmadinejad

Ali Rahnema

Cambridge Middle East Studies

\$95.00: Hb: 978-1-107-00518-1: 336 pp. \$28.99: Pb: 978-0-521-18221-8

The Politics of Inequality in Russia

Thomas F. Remington

\$90.00: Hb: 978-1-107-09641-7: 234 pp. \$29.99: Pb: 978-1-107-42224-7

Ruling by Statute

How Uncertainty and Vote Buying Shape Lawmaking

Sebastian M. Saiegh

\$90.00: Hb: 978-1-107-00565-5: 248 pp.

Building Global Democracy? Civil Society and Accountable Global Governance

Edited by Jan Aart Scholte

\$99.00: Hb: 978-0-521-19219-4: 424 pp. \$32.99: Pb: 978-0-521-14055-3

International Law in the U.S. Supreme Court Continuity and Change Edited by David L. Sloss, Michael D. Ramsey, and William S. Dodge

\$160.00: Hb: 978-0-521-11956-6: 654 pp.

Controlling Institutions

International Organizations and the Global Economy

Randall W. Stone

\$90.00: Hb: 978-1-107-00540-2: 272 pp. \$29.99: Pb: 978-0-521-18306-2
The Legislative

Legacy of Congressional Campaigns

Tracy Sulkin

\$85.00: Hb: 978-0-521-51449-1: 232 pp. \$25.99: Pb: $978-0-521-73048-8$

\section{Government}

versus Markets

The Changing Economic Role of the State

Vito Tanzi

\$35.00: Hb: 978-1-107-09653-0: 390 pp.

Global Warming Gridlock Creating More Effective Strategies for Protecting the Planet

David G. Victor

\$40.00: Hb: 978-0-521-86501-2: 392 pp.

Young Thomas More and the Arts of Liberty

Gerard B. Wegemer

\$85.00: Hb: 978-0-521-19653-6: 224 pp.

\section{Understanding}

Russian Politics

Stephen White

\$99.00: Hb: 978-0-521-86857-0: $488 \mathrm{pp}$. \$38.99: Pb: 978-0-521-68861-1

\section{Oligarchy}

Jeffrey A. Winters

\$95.00: Hb: 978-1-107-00528-0: 344 pp. \$29.99: Pb: 978-0-521-18298-0

Activists, Alliances, and Anti-U.S. Base Protests

Andrew Yeo

Cambridge Studies in Contentious Politics

\$90.00: Hb: 978-1-107-00247-0: 240 pp. \$27.99: Pb: 978-0-521-17556-2

Economic Choices in a Warming World

Christian de Perthuis

Translated by

Michael Westlake

\$75.00: Hb: 978-1-107-00256-2: 260 pp. \$27.99: Pb: 978-0-521-17568-5

Prices subject to change. 


\section{CAMBridge}

\section{JDURNALS}

In 2011,

Cambridge University Press

is delighted to begin publishing

Ethics \&

International Affairs

for the Carnegie Council for Ethics in International Affairs

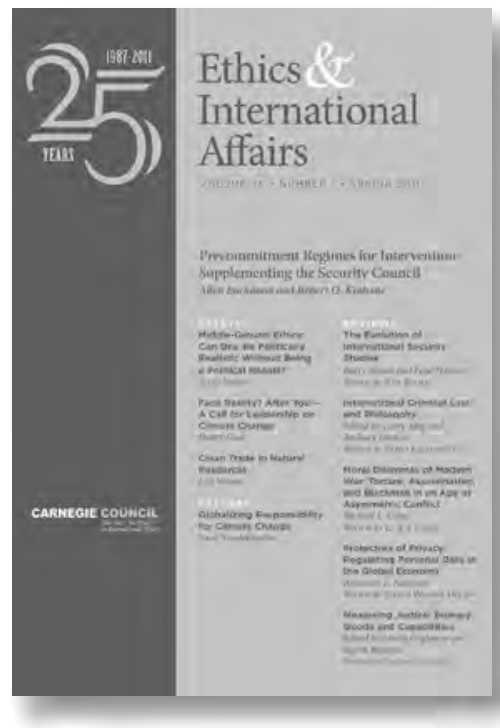

Editor-in-Chief:

Joel H. Rosenthal

Carnegie Council for Ethics in International Affairs, USA

Ethics \& International Affairs aims to help close the gap between theory and practice (and between theorists and practitioners) by publishing original essays that integrate rigorous thinking about principles of justice and morality into discussions of practical dilemmas related to current policy developments, global institutional arrangements, and the conduct of important international actors. Theoretical discussions that originate in philosophy, religion, or the social sciences should connect with the interests of journalists, activists, policy-makers, and citizens who are primarily concerned with assessing and reforming specific policies, as well as existing rules and institutions such as the United Nations, the World Bank, and the International Monetary Fund; arrangements governing trade, environmental protection, and the use of force; and the International Criminal Court and ad hoc tribunals that address genocide and past societal injustices.

FREE email alerts. Keep up-to-date with new material. Sign up at: http://journals.cambridge.org/eia-alerts

\section{journals.cambridge.org/eia}




\section{CAMBRIDGE JDURNALS}

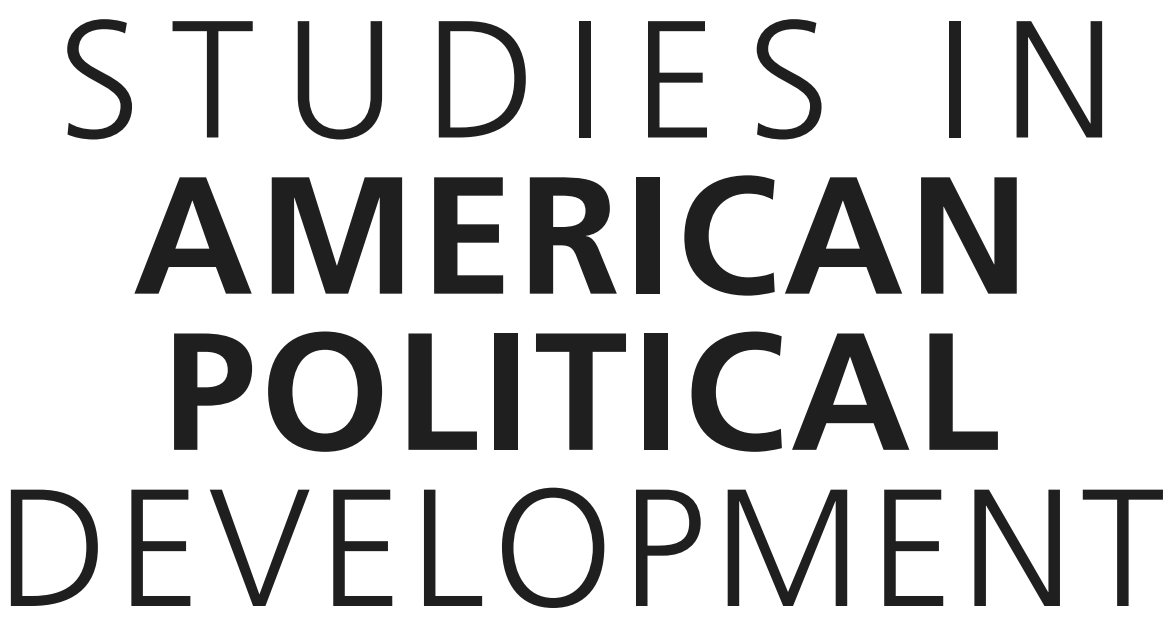

Editors:

STUDIES IN

AMERICAN

POLITICAL

DEVELOPMENT

Daniel Carpenter, Harvard University

Elisabeth Clemens, University of Chicago

Scott James, University of California, Los Angeles

Studies in American Political Development

VOLUME 25

NUMEER

publishes scholarship on political change and institutional development in the United States from a variety of theoretical viewpoints.

Articles focus on governmental institutions over time and on their social, economic and cultural setting. In-depth presentation in a longer format allows contributors to elaborate on the complex patterns of state-society relations.

Studies in American Political Development encourages an interdisciplinary approach and recognizes the value of comparative perspectives.

FREE email alerts. Keep up-to-date with new material. Sign up at: journals.cambridge.org/sap-alerts

Recommend SAPD directly from its homepage FRE online access for you when your library subscribes.

journals.cambridge.org/sap 


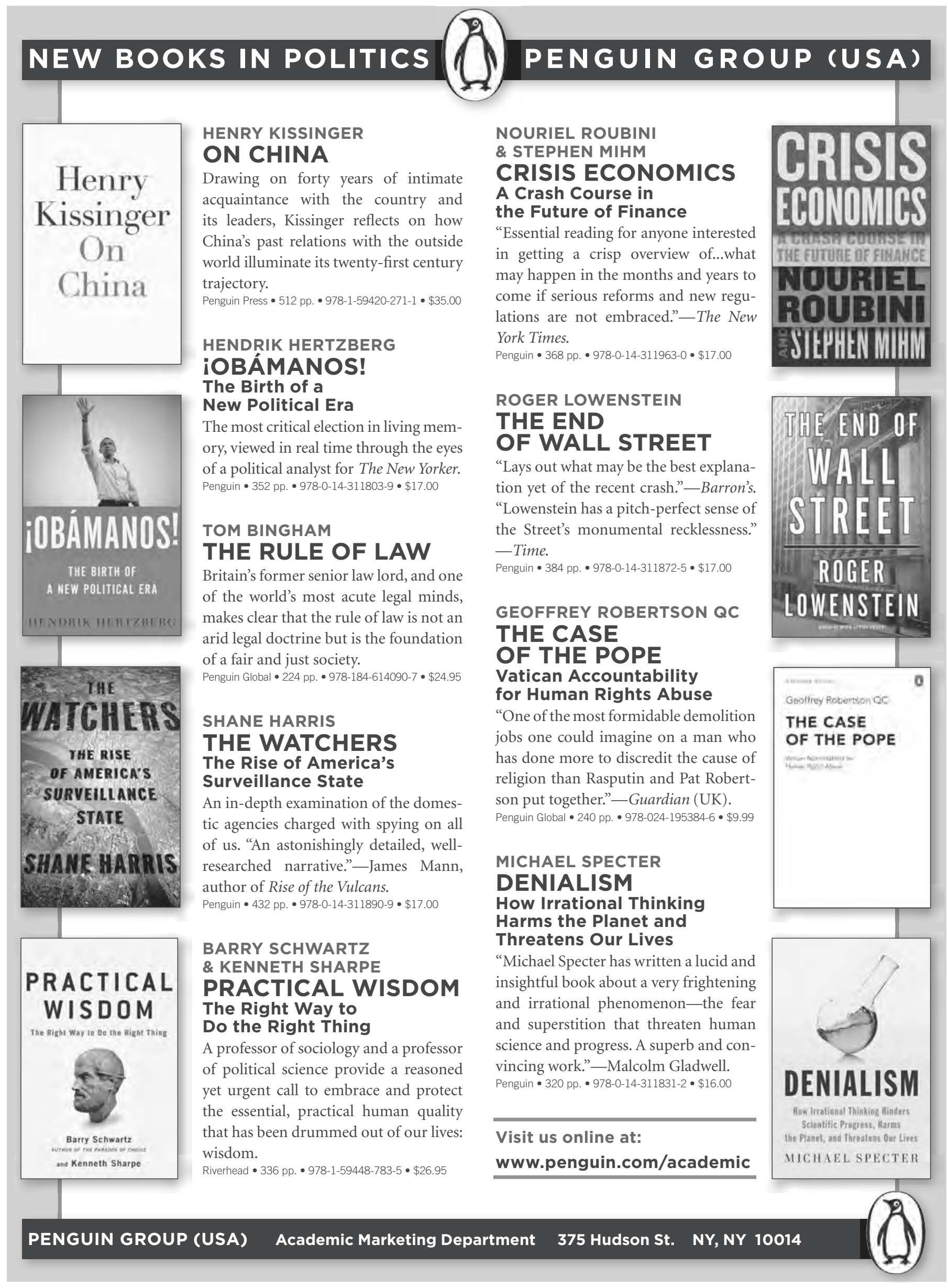




\section{Announcing SEIE 12}

New features include:

- Structural equation modeling (SEM). Flexible extension of multivariate regression, seemingly unrelated regression (SUR), instrumental variables, and FIML and LIML estimation of simultaneous systems. Direct and indirect effects. Implemented for big datasets and big models. Maximum likelihood estimation, GMM estimation, and maximum likelihood estimation for data missing at random (MAR).

- Multiple imputation (MI). Chained equations. Imputation of continuous, ordinal, cardinal, and count variables. Imputation separately within group. Imputation and estimation for panel data and multilevel models. Linear and nonlinear predictions. Survey support.

- Multivariate GARCH. Autoregressive models of volatility. Conditional heteroskedasticity. Constant conditional correlations (CCC). Dynamic conditional correlations (DCC). Varying conditional correlations (VCC). Normal errors. Student's $t$ errors. Prediction of levels or variances. Dynamic forecasts.

- Autoregressive fractionally integrated moving-average models (ARFIMA). Longmemory processes. Predictions. Dynamic forecasts.

- Unobserved components model (UCM). Trend, seasonal, and cyclical components. Prediction of components. Dynamic forecasts.

- Spectral density. Parametric estimates after ARIMA, ARFIMA, and UCM. Compare components. Compare frequencies. Graphs.

- Time-series filters. Decompose into trend and cycle. Baxter-King band-pass filter. Christiano-Fitzgerald band-pass filter. Butterworth high-pass filter. HodrickPrescott high-pass filter.

- Business calendars. Set up trading days, etc. User defined. Fully integrated. Conversion to and from regular calendar.

- Contrasts and pairwise comparisons. Compare means, intercepts, and slopes. Compare adjacent categories. Compare with reference category or grand mean. Orthogonal polynomials. Adjust for multiple comparisons. Treatment effects. Graph effects and potential outcomes.

- More multilevel/mixed models. Estimation with complex survey data.

- More data management. Excel ${ }^{*}$ import and export. EBCDIC. ODBC connection strings. PDF export of results and graphs.

- More ROC analysis. Adjustments for covariates.

- More survey analysis. Bootstrap and successive difference replicate (SDR) weights.

- Installation Qualification. Report for submission to regulatory agencies.

- More support for multicore computers. More estimators. Up to 64 cores supported.

- Automatic memory management. Up to 1 terabyte of memory.

\section{Now shipping. Visit www.stata.com/stata12}

Serious software for serious researchers. Stata is a registered trademark of StataCorp LP, 4905 Lakeway Drive, College Station, Texas. Serious software for serious researchers is a trademark of StataCorp LP. 800-STATAPC (800-782-8272). 800-248-8272 (Canada). 979-696-4600. 979-696-4601 (fax). service@stata.com. Fxcel is a registered trademark of Microsoft.

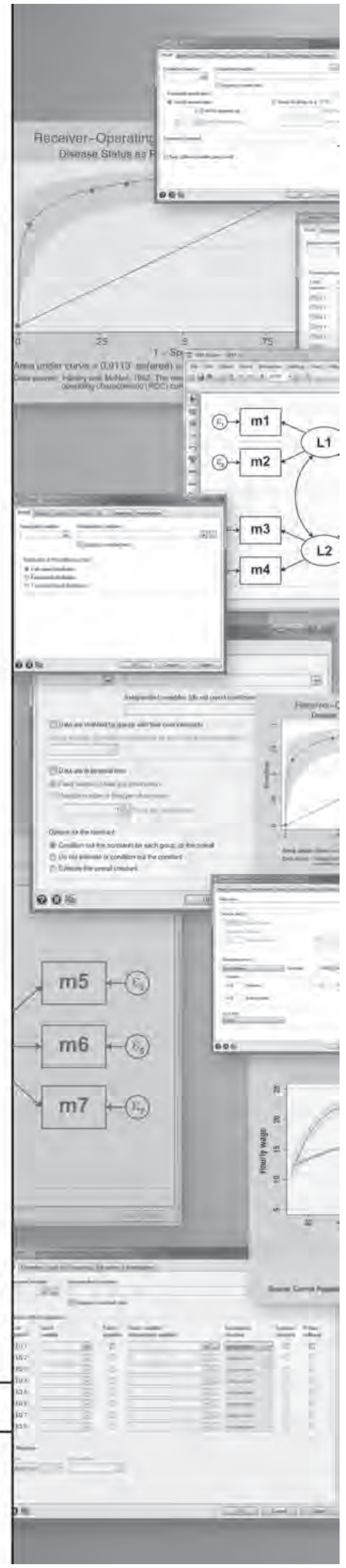

